Thís description of the case has been given, and the illustrations have been added to it, in order to direct attention to the fact that in certain morbid conditions of the intestinal mucous membrane the ingestion of nutritious articles of diet may not only lead to a continuance of the intestinal symptoms, but may have a special bad effect on the nutrition of some parts of the body which should not be ascribed to simple starvation, but which, in my opinion, is due to some unknown poison generated in the intestinal canal. In this man's case the cerebro-spinal nervous system, and the growth of the horny epithelium from which the nails are built up, were specially affected by this poison. (As a matter of subsidiary interest, it may be noted that the length of good nail shown in the illustrations represents six months' growth).

In connection with the modus operandi of milk diet in these cases the question suggests itself, Is it the milk that cures the disease, or does the disease get well because the other foods which the patient was taking are excluded? I have frequently observed that patients suffering from psilosis, and who have been doing well on exclusive milk diet for wf ek? experience a severe relapse as soon as a raw or lightly koiled egg is taken, or a cupful of arrowroot given. In such cases the relapse could not be due to any mechanical irritation produced by the egg or arrowroot, and I can only infer that it is caused by those substances constituting a pabulum for the development of some form of fermentation which does not occur when milk alone is given. I infer that an active cause of some abnormal fermentation can develop in eggs and arrowroot, beef tea, etc., but cannot grow in milk or its products during digestion.

In all cases of psilosis there is evidence of much abnormal fermentation in the intestinal canal. In this disease the fluid fæces are often so charged with gases as to cause the surface of the motion to be covered with air bubbles, the fermentation continuing for some time after they have been passed. A small (I ounce) bottle of semi-liquid fæces was recently sent to me for microscopical examination, the stopper being firmly tied down with string. On cutting the string the pressure of the gas that had be en evolved after the stopper was fastened was so great, that it was ejected with violence, with a sound like that caused by the ejection of the cork of a gingerbeer bottle when the wire is incautiously undone.

The anæmia in psilosis, as I have shown in greater length and detail in my book, is probably due to the effect of some poison associated with the abnormal fermentation. It is sometimes so great that I have known a case of true psilosis diagnosed by a distinguished physician as one of essential pernicious ânæmia. That the anæmia is not due so much to defective nutrition as to the destructive effect on the blood formation caused by the absorption of the poisonous product of fermentation in the intestine, is shown by the rapid improvement that takes place in the number of the red corpuscles when all food is withdrawn except a small amount of milk. In this connection I may refer to the opinion expressed by the late Sir Andrew Clark, ${ }^{2}$ that the anæmia of young women in chlorosis is due to a functional derangement of the intestinal canal, and should be treated by purgatives.

There are other diseases which are probably due to a similar cause. Gout, for example, so common and yet so little understood, is clearly associated with some persistent error in digestion, and if some physician whose opportunities are sufficient were bold enough to treat a series of cases of gout by exclusive milk diet, it would be of great interest to know the result.

I was much struck a number of years ago by the effect of an exclusive milk diet in a severe and fully-developed case of lupus erythematosus, which had been under my care. A woman, in the prime of life, had the fully-developed batwing form of the disease, the nose and both cheeks being affected, and during the few months that she was under my care did not materially improve. She disappeared from my observation, and when I next saw her (a considerable time afterwards) the disease bad entirely disappeared and the skin was healthy. On inquiring how this had happened, she told me that she had developed some serious abdominal (as I understood her, uterine) affection, for which a physician in Glasgow put her in bed and on exclusive milk diet, and whilst she was under this treatment the lupus erythematosus gradually faded, and eventually disappeared and never returned. I need hardly say that I prescribed the milk treatment for subsequent cases of lupus erythematosus, but unfortunately never again observed the same curative effect.

1 Psilosis or "Sprue": its Nature and Treatment: $w^{\text {th }}$ 'Observations on Various forms of Diarrhoa acquired in the Tropics. Second and enlarged edition. London: J. and A. Churchill. r897. 2 BRITISH MEDICAL JoURNsL, November igth, r887, pp. Iro6. Report of a meeting of the Medical Society of London.

\section{NOTES ON A CASE OF ACROMEGALY.}

BY JOHN NORCOTT D'ESTERRE, M.R.C.S., L.R.C.P., Eastbourne.

J.H., male, aged 39 , married; has four children, who are all healthy. His family history is good, and there is no history of a similar complaint in the family. His personal history also is good; he never had any illness until seven Jears ago, when he had an attack of influenza, after which he noticed his nnder lip and tongue swelling, and his hands and chest enlarging.

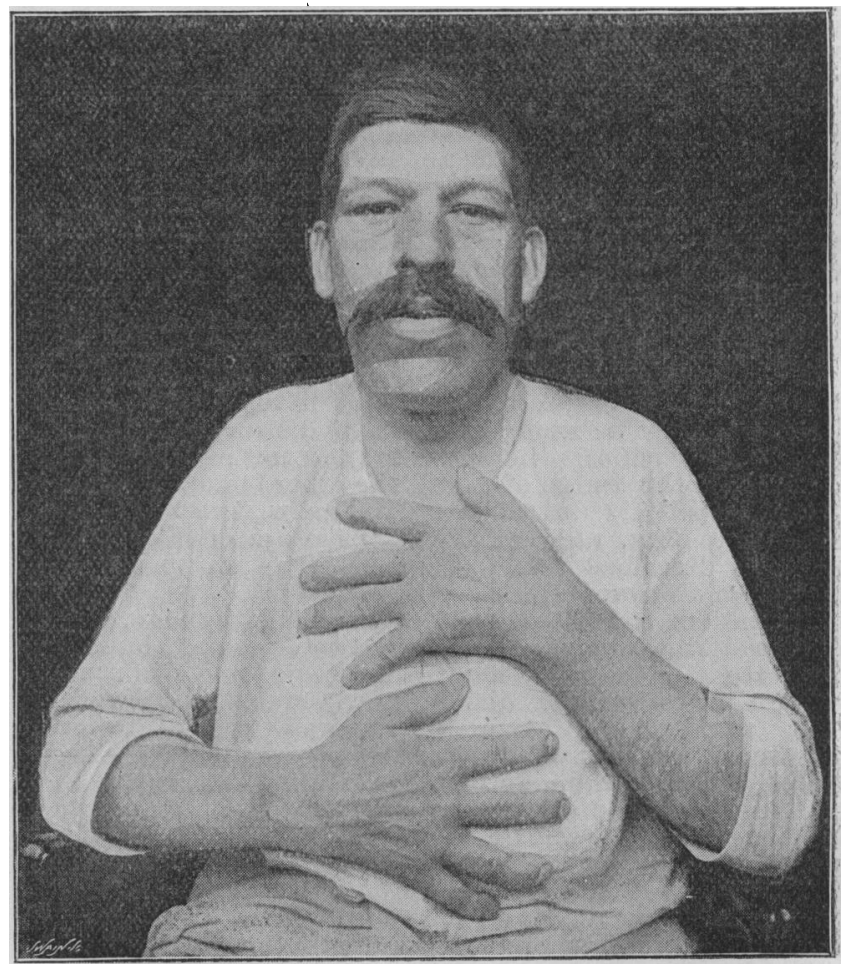

1 first saw mun on dugust 24lh, 1897 , when 1 fuund that he was a well-nourished man with ponderous and large hands, and that his feet also were larger than normal, but not to such a degree as the hands. His features were heavy, with a very large, thick, projecting under lip, massive underjaw (due to bony growth, and not to any subcutaneous deposit); the teeth of the lower jaw projected in front of those in the upper, and were spreading. The cartilages of the nose and ears were greatly thickened, and probably those of the larynx, as his voice, he informed me, had altered of late to a deep bass. He had prominent frontal eminences, with deep hollows in both temporal fosex. The skin of the face was slightly pigmented, the orifices of sweat glands enlarged. The senses of smell, taste, and hearing were good. The tongue was enormously enlarged, so much so that when he opened his mouth it appeared to fill the entire cavity. The tonsils and uvula were also enlarged. He complained of difficulty in swallowing at times, and of slight asthmatic seizures. In form the face was ovoid. His eyesight was getting woree, and 
optic neuritis was present. By the perimeter he was found to have well-marked bitemporal hemianopia, the nasal half of the field of vision being perfect. He did not suffer from headaches, but if he stooped he felt as though his head was swelling and would burst. The ribs were quite twice the thickness of normal ones, and markedly thickened at the sternal ends. The sternum was enlarged to a considerable degree, and projects forward. The heart was normal. The spleen and liver were not examined. There was no apparent enlargement of the thyroid. He perspired very freely, and suffered much from thirst. He constantly felt drowsy. Memory for recent events was very bad, but he remembered things that happened years ago well. His gait was slow, measured, with a pronounced stoop, and he had difficulty in getting up and down stairs. Both knees and shoulders were affected with rheumatoid arthritis. In the nineteen days he was under my observation he lost 4 lbs.

REMARKS.

Since August 24th, 1897, the patient has been taking tabloids of "pituitary gland substance," gr. ii (B. W. and Co)., three times a day, with the following result, which I give in his own words, his letter to me being dated November 8th : "I certainly feel much more active than I did, and have lost 8 lbs. since my return from Eastbourne."

\section{VOLVULUS OF MECKEL'S DIVERTICULUM.}

By THOS. CARWARDINE, M.S., F.R.C.S., Assistant Surgeon, Bristol Royal Infirmary.

L. P., aged 2 days, was brought to the Bristol Royal Infirmary on October 15 th, 1897 , on account of intestinal obstruction. The child had been repeatedly sick, bringing up a greenish-brown vomit, and had passed nothing per anum, nor discharge from umbilicus. The belly was much distended, and exploration of the rectum with the finger revealed no cause. The child was watched and treated for six hours, but nothing passed.

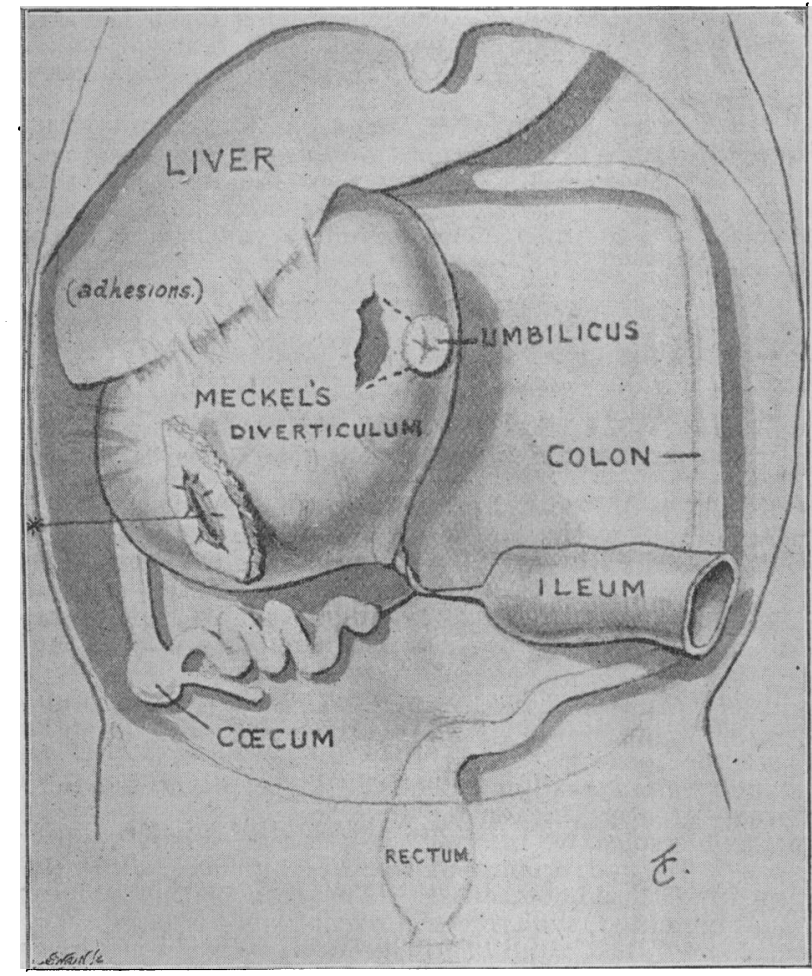

* Enterostomy aperture, with skin attached.

Operation.-The distension appeared more on the left side, and accordingly coliotomy was performed in the left semilunar line. Here the small intestine prosented, very much distended, with lymph upon its surface from peritonitis. The colon, when brought to the surface, was very small, not larger than a crow quill, whitish, empty, and non-sacculated. With the finger in the abdomen I could feel bimanually a mass to the right of the umbilicus. A second incision was therefore made in the right semilunar line, when much distended gut presented, which it was impossible to bring out of the opening, owing to numerous adbesions; and for the same reason the source of obstruction could not be felt, although it seemed almost certain that it was due to an anomaly of Meckel's diverticulum. On making an artificial anus, a considerable quantity, several ounces, of meconium escaped. The cæcum and ascending colon were small, white, and empty. The symptoms persisted, and the child died twentyfour hours later. At the post-mortem examination it was found that a meconium-containing cyst had been opened, produced by a volvulus of Meckel's diverticulnm of some three tarns, as in the figure. Only a fine impervious cord connected it with the bowel below it, and a minute stalk, which would partially admit a bristle, attached it to the distended bowel above, the junction being a $\perp$-shaped one. are :

The points of interest to which attention should be drawn

I. The ante-partum commencement of peritonitis, as shown by the lymph and adhesions of firm character to parts around.

2. The occurrence of the volvulus of Meckel's diverticulum in utero, during late fotal life, so that a meconium-containing cyst was segmented off from the meconium-containing ileum, and therefore obstruction was not relieved by opening the distended diverticulum.

3. The lower 12 inches of small intestine were empty and tortuous, and the colon small and non-sacculated. No meconium had ever passed into them, yet the cæcum and appendix were well formed. This disposes of a common view as to the development of the cæcum.

\section{TRAUMATIC ANEURYSM OF THE ULNAR ARTERY IN THE PALM CURED BY TYING THE ULNAR ARTERY ABOVE THE WRIST.}

By WM. ROBERTSON, M.D.GLas., D.P.H., Assistant Visiting Surgeon and District Physician to the Perth County and City Royal Infirmary.

In the British Medical Journal of September inth Dr. Griffiths has an interesting notice of a case of spontaneous aneurysm of the ulnar artery; and, as he prefaces his report with the remark that aneurysms of small arteries are rare, I am glad to be able to chronicle a somewhat similar case. In this instance there was a distinct cause for the disease; in other words, the aneurysm was traumatic. Briefly, this is the history of the case.

W. G., aged 18, fireman on a railway engine, when seen at the infirmary on August 25 th, complained of a painful spot just under the hypothenar eminence of the left hand. On comparing the two hands one could plainly detect a bulging at the affected part. And with this bulging a pulsation was very noticeable. He had more than once remarked on the " beating." It was, however, the pain that worried him. The swelling was nearly an inch in diameter, and almost circular. When its centre was firmly palpated the pain was increased. Only occasionally had he felt any numbness of the little finger and its neighbour. The patient was a healthy, strapping fellow, muscular and well developed. His heart was normal, and he had never suffered from cough. There was no syphilitic history ; indeed, he had never had a day's illness.

The pulsation in the aneurysm entirely ceased when the ulnar artery was firmly compressed above the wrist. The interesting part of the case lies in the fact that the traumatic cause is distinct. About five months ago W. G. found the injector of his engine very stiff. He gave it a firm knock with his left hand. This caused a sharp pain in the hypothenar eminence. The tenderness was only aggravated by the persistent knocking required to force the handle of the injector. The swelling and pulsation in the hand were noticed for the first time two months ago. This led him to consult a doctor, who recommended painting with iodine. 